Revista Verde de Agroecologia e Desenvolvimento Sustentável

http://www.gvaa.com.br/revista/index.php/RVADS

ARTIGO CIENTÍFICO

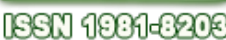

DOI: http://dx.doi.org/10.18378/rvads.v10i4.3496

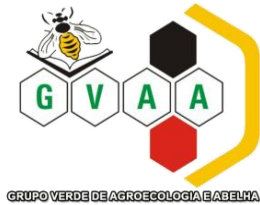

\title{
Análise sensorial e desenvolvimento de embalagem para aguardente de algaroba
}

\section{Sensory analysis and packaging development for brandy mesquite}

\author{
Viviane Brasileiro de Holanda ${ }^{1}$, Analha Dyalla Feitosa Lins ${ }^{2}$, Mário Eduardo R.M. Cavalcanti Mata ${ }^{3}$, Maria Elita Martins \\ Duarte $^{3}$, Regilane Marques Feitosa ${ }^{4}$
}

\begin{abstract}
Resumo: Objetivou-se com esse estudo realizar análise sensorial da aguardente de algaroba, desenvolver uma embalagem para sua comercialização e verificar a preferência de embalagem pelo seu aspecto visual. De acordo com a análise sensorial através do teste afetivo com 30 voluntários, detectou-se que quanto ao sabor não houve diferença para os avaliadores e a embalagem de vidro teve uma maior aceitação quanto à preferência em razão de conservar melhor as qualidades organolépticas da bebida que a embalagem PET, sendo este, portanto, o melhor material para o acondicionamento da aguardente. Para o processo de criação da embalagem fez-se uma pesquisa de campo, geração de conceitos e posteriormente uma análise de preferência visual dos conceitos, sendo o conceito 1 o escolhido para a embalagem da aguardente de algaroba, e a embalagem que confere maior requinte com formas arredondadas que remetem à vagem da algaroba, apresentou uma diferença de apenas $3,1 \%$ de preferência.
\end{abstract}

Palavras-chaves: Prosopis juliflora (Sw.) DC.; sabor; preferência; vidro; PET.

Abstract: The aim of this study perform sensory analysis of mesquite brandy, develop packaging for its commercialization and check the preferred packaging for its visual appearance. According to the sensory analysis through affective test with 30 volunteers, it was detected that in taste no difference to the evaluators, being that the glass packaging had a greater acceptance as the preferred due to better conserve the organoleptic qualities of the drink that PET packaging and this is the best material for the packaging of spirits. For the process of creating the package was made a field research, generating concepts and further preferably a visual analysis of the concepts, being the chosen concept for the packaging of mesquite brandy was the first concept, the packaging that gives greater refinement with rounded shapes that refer to mesquite pod, It showed a difference of only $3.1 \%$ preferably

Key words: Prosopis juliflora (Sw.) DC.; flavor; preference; glass; PET.

\footnotetext{
*Autor para correspondência

Recebido para publicação em 08/07/2015; aprovado em 28/09/2015

${ }^{1}$ Mestre em Engenharia Agrícola, Profa. Assistente II, UFCG, Campina Grande, Paraíba. E-mail: vivianebrasileiro2@hotmail.com

${ }^{2}$ Mestranda em Engenharia de Agrícola, UFCG, Campina Grande, Paraíba. E-mail: dyallalins@gmail. Com

${ }^{3}$ Eng. Agrícola, Prof. Associado, Unidade Acadêmica de Engenharia de Alimentos, UFCG, Campina Grande, Paraíba. E-mail: mmata@ deag.ufcg.edu.br; elita@deag.ufcg.edu.br

${ }^{4}$ Tecnóloga de Alimentos, Pesquisadora PNPD/CAPES, Engenharia de Processos, UFCG Campina Grande, Paraíba. E-mail: regilanemarques@yahoo.com.br
} 


\section{INTRODUÇÃO}

As aguardentes de frutas são aquelas obtidas do destilado alcoólico simples a partir do suco integral, do suco concentrado ou da polpa (BRASIL, 2011). No Brasil, a aguardente mais popular é a de cana-de-açúcar, mais conhecida por cachaça. A produção estimada é de 1,3 bilhões de litros por ano com mais de 5 mil marcas registradas e cerca de 40 mil produtores em todo o país, de acordo com o Instituto Brasileiro de Cachaça (IBRAF, 2008).

Atualmente existem várias fábricas de aguardente (formais e informais), não só de cana-de-açúcar, mas também de outras matérias-primas. Diante disso, estudos estão sendo realizados para produção de bebidas destiladas a partir de matérias-primas ricas em açúcares susceptíveis a fermentação, como abacaxi, sucos de kiwi, banana, mandacaru, laranja, uva e das vagens da algarobeira, pelo alto teor de sacarose presente no fruto. A fermentação das vagens produz álcool etílico, ácido acético e ácido cítrico, enzimas e muitos outros componentes secundários, como metanol e alcoóis superiores, que contribuem para a qualidade sensorial das bebidas (SILVA, 2009).

A análise sensorial dos produtos tem como intuito avaliar sua adequação ao consumidor específico (ABREU, 2011). Neste sentido, esta ciência usa de métodos com o objetivo de avaliar as propriedades dos produtos através das respostas dos consumidores, da interação entre eles (MINIM, 2013).

Os testes afetivos são utilizados quando se necessita conhecer o quanto o consumidor gosta ou desgosta do produto e, para isto, se utiliza a escala hedônica de 9 pontos. Dos valores relativos de aceitabilidade pode-se inferir a preferência, ou seja, as amostras mais aceitas são as preferidas e vice-versa (MIRANDA, 2005)

Além da necessidade de uma boa qualidade sensorial, com o surgimento e o crescimento dos supermercados, as embalagens precisam cada vez mais ser auto-suficientes, tornando-se as "próprias vendedoras" dos produtos que embalam. As mesmas devem ter características que chamem a atenção do consumidor; devem ser funcionais, diferentes das demais concorrentes e atraentes visualmente.

Assim, objetivou-se com esse estudo realizar análise sensorial da aguardente de algaroba, desenvolver uma embalagem para sua comercialização e verificar a preferência de embalagem pelo seu aspecto visual.

\section{MATERIAL E MÉTODOS}

Para a fabricação da aguardente de algaroba (Prosopis juliflora (Sw.) DC.) foram colhidas vagens, oriundas da mesorregião do Cariri paraibano. As leguminosas foram cortadas manualmente e imersas na água, na proporção de $3: 1$, pelo tempo aproximado de 3 horas. Após cortadas e hidratadas, foram prensadas até atingir uma força de 8 toneladas. Depois da prensagem, o caldo passou por uma diluição com o intuito de ajustar alguns parâmetros exigidos: brix $-18^{\circ}, \mathrm{pH} 4,5$ e temperatura de $28^{\circ} \mathrm{C}$, passando a ser chamado de mosto. Para a fermentação do mosto utilizou-se o fermento (Sacharomyces cerevisiae) decorrendo o tempo de aproximadamente 16 horas. Posteriormente, ocorreu a destilação por aproximadamente 45 minutos. A aguardente foi bidestilada, ou seja, constitui dupla destilação, na qual se utiliza o corpo proveniente da primeira destilação para a realização de uma nova destilação. O teor alcoólico da aguardente foi de $41,5^{\circ} \mathrm{GL}$. Após a obtenção foi envasada em embalagem PET e vidro.

\section{- Análise sensorial}

A análise sensorial foi realizada no LAPPA (Laboratório de armazenamento e processamento de produtos agrícolas da UFCG), com a participação de 30 voluntários não treinados com idade entre 20 e 60 anos. Esta análise foi divida em duas etapas. Na primeira a aguardente foi recém-destilada, com o intuito de verificar, através do teste afetivo com escala hedônica, o quanto os provadores gostaram ou não da bebida; já a etapa seguinte foi realizada após 120 dias de armazenamento, com o propósito de constatar se ocorreu alguma mudança perceptível no sabor da aguardente armazenada nos dois tipos de embalagem (vidro e PET). O método utilizado para a análise sensorial da aguardente foi o teste afetivo, método através do qual se pode avaliar grande número de consumidores, a respeito de sua preferência gosto e opinião.

\section{- Processo de criação da embalagem \\ - Pesquisa de campo}

A definição e análise do público-alvo da aguardente foi realizada fora dos laboratórios e salas de aula, o público-alvo escolhido foi composto de pessoas na faixa etária dos 30 aos 40 anos,. Para o desenvolvimento da criação da embalagem foi realizada uma pesquisa em um possível local de venda e consumo; por fim, foram catalogadas imagens variadas que serviram de base para a criação da mesma.

- Geração de conceitos

Etapa na qual todas as pesquisas, juntamente com os requisitos, foram usadas para gerar as alternativas de embalagens. Utilizou-se a técnica de brainstorming, na qual todas as idéias, independente de serem boas ou não, são colocadas no papel; posteriormente, realizou-se a triagem analisando-se que idéias devem ser desenvolvidas.

\section{- Análise de preferência visual dos conceitos}

Depois de gerados os conceitos das embalagens realizou-se a análise de preferência visual, na qual os 32 voluntários mostraram, através de uma enquete, o conceito preferido. Foi apresentado para os voluntários, as três imagens das embalagens (desenho 3D) para que eles indicassem a de sua preferência. Após essa pesquisa foi, definido o conceito de melhor aceitação entre os entrevistados, e gerado um rótulo para este conceito.

\section{-Análise estatística}

Os dados experimentais foram analisados estatisticamente, através do programa computacional ASSISTAT versão 7.5, através do teste de Tukey a 5\% de probabilidade.

\section{RESULTADOS E DISCUSSÃO}

\section{- Análise sensorial}

Verificam-se, na Tabela 1, os valores médios das notas do teste de ordenação de preferência entre a aguardente acondicionada em vidro e em PET e as notas do teste afetivo (inicial, vidro e PET), onde se utilizou a escala hedônica. 
Tabela 1- Resultado da análise sensorial

\begin{tabular}{llc}
$\begin{array}{l}\text { Material da } \\
\text { embalagem }\end{array}$ & Sabor & Preferência $(\%)$ \\
\hline Inicial & $5,666 \mathrm{a}^{*}$ & - \\
Vidro & $5,333 \mathrm{a}^{*}$ & 56,6 \\
PET & $5,200 \mathrm{a}^{*}$ & 43,33 \\
\hline
\end{tabular}

*Significativo a $5 \%$ de probabilidade

Observa-se assim, que as notas de avaliação do sabor da aguardente foram semelhantes, não havendo diferença significativa entre elas. Observou-se uma diferença perceptível com relação à preferência da aguardente (PET ou vidro) em que, $56,6 \%$ dos avaliadores preferiram a aguardente acondicionada em vidro. Os outros avaliadores, 43,3\%, preferiram a aguardente acondicionada em PET.

Verifica-se, na Tabela 2, que na faixa etária de 30 aos 40 anos de idade não houve diferença significativa nas médias das notas atribuídas para o sabor da aguardente; a média de notas para a aguardente acondicionada em vidro foi de 5,33, enquanto para a aguardente acondicionada em PET foi de 5,06 , porém, mesmo não tendo uma diferença significativa nas notas, verifica-se que o percentual de voluntários que preferiram a aguardente armazenada em vidro, -foi, de 66,6\%, contrastando com 33\% de voluntários que preferiram a aguardente em PET; constata-se, portanto, que nessa faixa etária, a porcentagem de pessoas que preferiram o vidro é significativamente maior que a porcentagem global.

Outra pergunta dirigida aos voluntários foi: qual das duas aguardentes (acondicionada em vidro ou PET) se aproximava mais, em relação ao sabor, da aguardente inicial (Gráfico 1). Constatou-se que 53,3\% dos voluntários afirmaram que a aguardente armazenada em vidro se aproximava mais da inicial; em contrapartida, 26,6\% dos voluntários afirmaram que a aguardente armazenada em PET é mais semelhante à inicial; o restante dos voluntários (20\%) não opinou a respeito.
Gráfico 1- Opinião dos voluntários a respeito de qual aguardente é mais parecida com a inicial

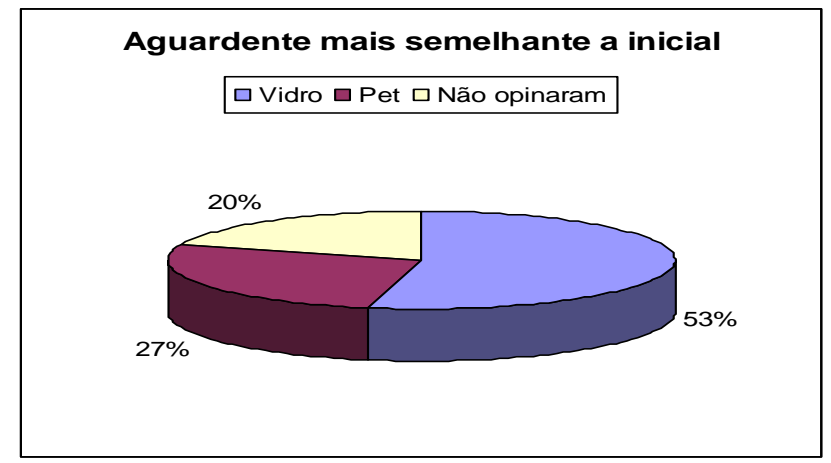

Silva et al. (2014) realizou uma pesquisa sobre a aceitação da aguardente de algaroba no mercado Na pesquisa, foi perguntado se os mesmos estariam dispostos a consumir uma aguardente produzida a partir das vagens de algarobeira e $62 \%$ responderam que Consumiriam, 32\% que Talvez e $6 \%$ optaram pela opção que Não consumiriam. Além de consumir, os entrevistados responderam se comprariam esta aguardente, com 53\% afirmando que Comprariam, 38\% que Talvez e 9\% que Não/Nunca. Os resultados obtidos apontaram que os entrevistados estão dispostos a consumir e adquirir uma aguardente produzida a partir das vagens de algarobeira e apenas uma minoria rejeitaria essa idéia.

Cardello e Faria (2000) analisaram 11 amostras de aguardentes de cana envelhecidas e não envelhecidas por testes sensoriais afetivos e análises estatísticas uni e multivariada. As amostras de aguardente envelhecidas por 12, 36 e 48 meses obtiveram maior aceitação, com médias ao redor de 7,0 na escala hedônica. A amostra com menor aceitação foi a correspondente ao tempo zero de envelhecimento (controle). As demais amostras obtiveram aceitação intermediária.

Tabela 2-Resultado da análise sensorial por faixa etária

\begin{tabular}{cclccc}
\multirow{2}{*}{ Faixa etária } & \multirow{2}{*}{ Quantidade de pessoas } & Sabor (média de notas) & \multicolumn{2}{c}{ Preferência (\%) } \\
\cline { 3 - 6 } & & Vidro & PET & Vidro & PET \\
\hline $20-29$ & 8 & 5,1 & 5,6 & 50,0 & 37,5 \\
$30-39$ & 15 & 5,3 & 5,1 & 66,6 & 33,0 \\
$40-49$ & 4 & 5,5 & 5,5 & 50,0 & 25,0 \\
$50-60$ & 3 & 6,0 & 5,7 & 66,0 & 0,0 \\
\hline
\end{tabular}

\section{- Criação da embalagem - Diretrizes do projeto}

O material escolhido para a embalagem foi o vidro pois baseado em estudos anteriores, o mesmo apresentou melhor conservação da aguardente de algaroba ao longo do armazenamento. Segundo Holanda et al. (2015), foi o material que menos alterou as propriedades da aguardente; outra qualidade conferida ao vidro é o fato da sua transparência além de suas inúmeras possibilidades de forma.

Segundo Kuchler e Silva (1999) o recipiente ideal para a aguardente é uma garrafa de vidro transparente e bem fechada, identificada com o nome da empresa, proprietário, endereço e telefone de contato. Câmara (2006) concorda com essa afirmação, dizendo que as garrafas de vidro sempre são preferidas e nunca de plástico nem outros materiais semelhantes, para o acondicionamento da aguardente.

A embalagem deverá ter um sistema de fecho prático para o usuário; deve comportar $700 \mathrm{ml}$; permitir que o consumidor veja que o produto seja diferente das demais embalagens encontradas no mercado, contendo algum elemento que remeta à algaroba.

\section{- Geração e seleção dos conceitos}

Segundo Carneiro et al. (2010) vários fatores como a cor da garrafa de vidro, o tipo da tampa, as ilustrações do rótulo, entre outros, são aspectos relevantes e devem ser observados na criação da embalagem.

Dentre as inúmeras soluções que surgiram a partir do "brainstorming", foram selecionadas três idéias que se adequavam melhor aos requisitos do projeto. Embora os três conceitos sejam diferentes, foram gerados a partir da vagem de algaroba. Em alguns casos, esta forma foi inserida de maneira mais ostensiva. Verificam-se nas Figuras 1, 2, 3 e 4, os conceitos da embalagem de aguardente de algaroba. 
A principal característica do conceito 1 é a elegância; nele, a forma da vagem foi colocada de maneira discreta. Pode-se observar na Figura 1 o detalhe da embalagem, que tem a forma da vagem de algaroba. A garrafa possui formas orgânicas que remetem diretamente à natureza. Para oferecer um requinte maior à embalagem, utilizou-se o efeito de vidro jateado que, além de ter caráter estético, também facilita no manuseio da garrafa, pois adere melhor, diminuindo o risco de escorregar das mãos. O detalhe do vidro jateado é em alto relevo, dando a impressão de que são duas partes de vidro acopladas. Para oferecer maior dinamismo ao produto, a base do vidro jateado é curva, harmonizando-se com as formas arredondadas da embalagem.

Figura 1. Imagens ilustrativas da criação da embalagem de vidro de aguardente de algaroba usando o Conceito 1. a. Garrafa em vidro; b. Vista da tampa da garrafa aberta. Tampa plástica com rosca; c. Vista Frontal; d. Vista lateral; e. Detalhe jateado da embalagem possui forma semelhante à da parte superior de algumas vagens de algaroba.
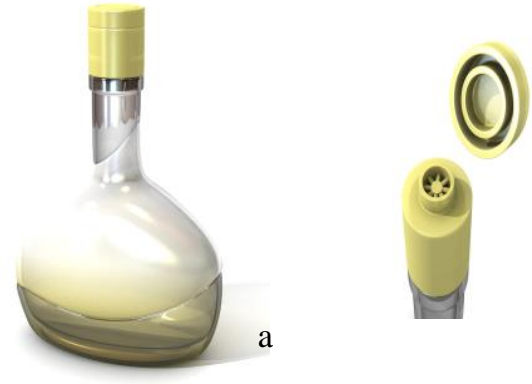

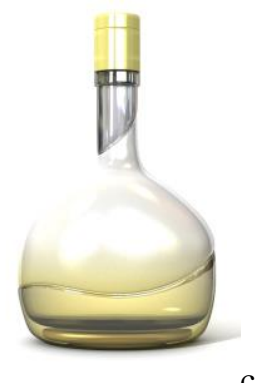

c
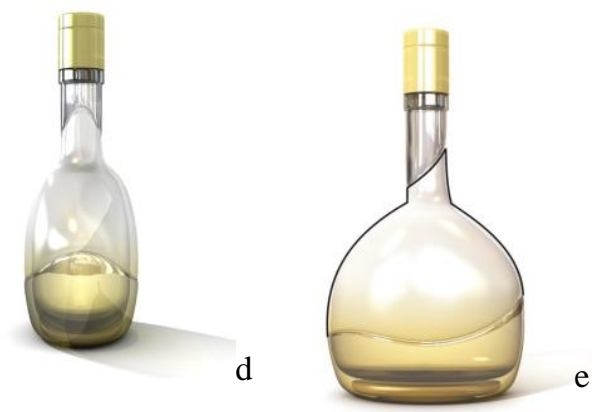

De acordo com Carneiro et al. (2010) na maioria das vezes, o consumidor de bebida sente a necessidade de verificar o produto que está comprando, analisando a cor e sua aparência, motivo pelo qual a maioria das bebidas possui embalagens transparentes que permitem a visualização do produto e para permitir esta visualização, a coloração foi colocada apenas na base da garrafa. Por se tratar de material translúcido, esses raios coloridos vão além da base, deixando um leve efeito degradê. Procurou-se utilizar uma cor próxima a cor da vargem, que de acordo com Silva (2009) é amarela claro.

Seu sistema de fecho é prático e moderno, haja vista que permite uma dosagem adequada da bebida, além de oferecer um aspecto moderno à embalagem; a tampa é plástica com coloração igual à da base da garrafa; este tipo de sistema de fecho, além de oferecer praticidade ao usuário, é o tipo de sistema utilizado para exportação.

$\mathrm{O}$ conceito se destaca das outras embalagens de aguardente, por sua beleza e elegância.

Figura 2. Imagens ilustrativas da criação da embalagem de vidro de aguardente de algaroba usando o Conceito 2. a. Garrafa em vidro com forma interna que remete diretamente à vagem da algaroba; b. Vista da tampa da garrafa aberta; c. Vista frontal; d. Vista lateral.
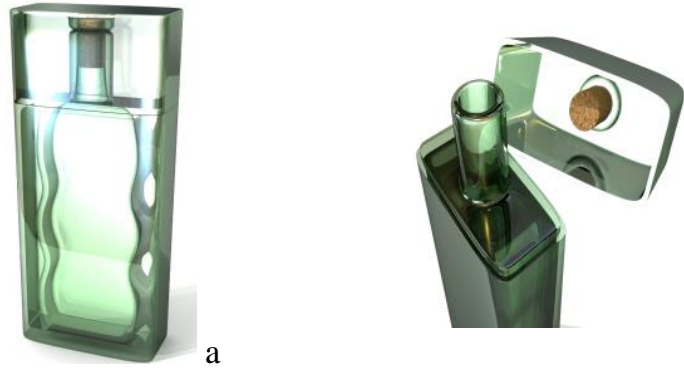

O principal aspecto do conceito 2 é a inovação. A aguardente de algaroba é um produto extremamente novo no mercado e este conceito buscou enfatizar a inovação. A embalagem com forma inovadora para o mercado de bebida alcoólica procurou transmitir, ao consumidor, um novo conceito de forma de embalagem de aguardente.

A garrafa tem sua forma externamente reta e possui internamente, sinuosidades que se identificam de maneira direta com a vagem de algaroba (Figura $2 \mathrm{c}$ ). A forma externa retilínea procura transmitir ao consumidor, a sensação de robustez, que contrasta com a sinuosidade delicada da parte interna. Da mesma maneira do conceito 1, a cor da embalagem foi colocada apenas na parte inferior, deixando-a

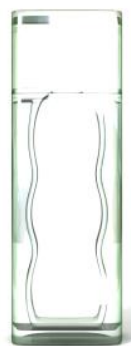

c

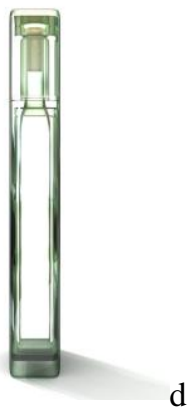

com uma leve tonalidade esverdeada. $\mathrm{O}$ verde foi escolhido com o intuito de atribuir à embalagem, correlação com a natureza.

O sistema de fecho da embalagem foi a cortiça, bastante adequada para a vedação de aguardente; a cortiça foi inserida em uma tampa de acrílico, para diminuir sua visibilidade, deixando a embalagem mais elegante.

Escolheu-se o acrílico para a fabricação da tampa, pois apesar de ser um material transparente, semelhante ao vidro, não se quebra com facilidade, visto que a tampa é uma peça da garrafa muito manuseada, com maior risco de cair.

O conceito 3 se destaca das demais embalagens por sua forma inusitada no mercado de aguardente. 
Figura 3. Imagens ilustrativas da criação da embalagem de vidro de aguardente de algaroba usando o Conceito 3.a. Garrafa em vidro com gomos que remetem à algaroba; b. Vista frontal; c. Vista lateral.

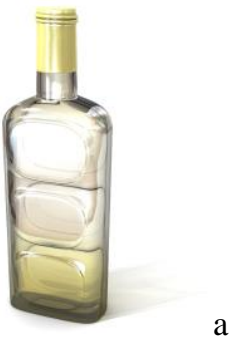

O conceito 3 é uma garrafa de vidro com gomos que remetem à algaroba, com tampa rosqueável de alumínio. tal conceito, embora apresente uma forma mais tradicional, nele se inseriram detalhes próprios da algaroba (gomos na garrafa em alto relevo) o que fez o diferencial da embalagem. Os gomos de vidro inseridos na garrafa, além de terem caráter estético, também facilitam o manuseio do produto.

Para que a garrafa não se tornasse grosseira, pensou-se em deixá-la mais estreita do que o convencional (para as garrafas retangulares). Apesar da forma reta, suas arestas são abauladas, deixando-a mais próxima às formas da natureza. A coloração da embalagem é apenas na base, com o intuito de se deixar parte da embalagem transparente, para que o consumidor possa verificar a aguardente. Seu sistema de fecho é tampa de alumínio, que oferece ao produto, praticidade e modernidade.

\section{- Conceito escolhido}

As opiniões dos entrevistados ficaram bastante divididas; no entanto, por uma diferença de $3,1 \%$, o conceito 1 foi o preferido. Observa-se, na Figura 4, a preferência que cada conceito obteve.

Gráfico 2- Preferência dos conceitos, com base na enquete realizada.

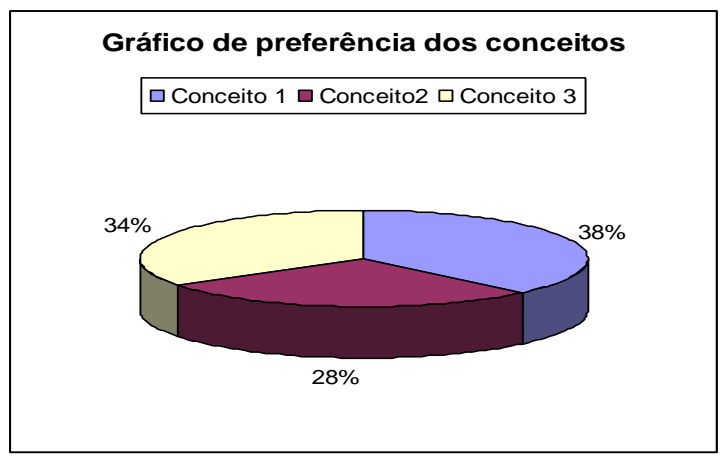

\section{Detalhamento da embalagem}

Depois que a embalagem (Conceito 1) foi escolhida, começou a criação do rótulo, o qual segue os padrões da garrafa, ou seja, continua transmitindo, ao consumidor, as mesmas sensações.

De acordo com Dias (2010) os rótulos das embalagens de aguardente buscam transmitir a cultura da região de origem, sua matéria prima e/ou modo de produção. $\mathrm{Na}$ pesquisa de campo realizada verificou-se que os rótulos das bebidas sofisticadas possuem, no geral, poucas cores, sendo mais discretos e elegantes. Dessa maneira houve a escolha da redução no uso das cores do rótulo. Embora o rótulo seja uma b

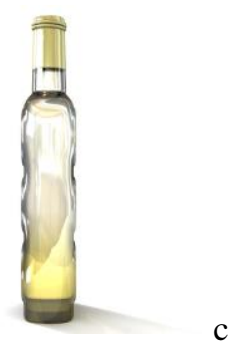

policromia, existem apenas 3 cores predominantes; as cores predominantes escolhidas para o rótulo, foram o preto, dourado e o marrom. De acordo com Souza (2008) o preto transmite sofisticação, poder e formalidade. O dourado, por remeter diretamente ao ouro, transmite elegância e nobreza. Embora os aspectos acima citados sejam de muita importância, outro aspecto que deveria ser enfatizado pelo produto, é a sua matéria-prima, ou seja, a algaroba; por este motivo, além da utilização discreta da imagem das vagens de algaroba inseriu a imagem de um campo com o intuito de transmitir ao consumidor, a relação da bebida com a natureza. A imagem de fundo é predominantemente marrom, cor que se associa facilmente à vagem de algaroba.

Embora a aguardente de algaroba seja um produto novo no mercado, tentou-se transmitir, ao produto aspecto de tradição, aspecto este que é o grande carro chefe da aguardente de cana-de-açúcar; esta tradição foi inserida no rótulo com a utilização de uma fonte clássica e rebuscada.

Figura 4- Rótulo da embalagem: Impresso em papel couché $115 \mathrm{~g} / \mathrm{m}^{2}$, com a utilização de verniz total.

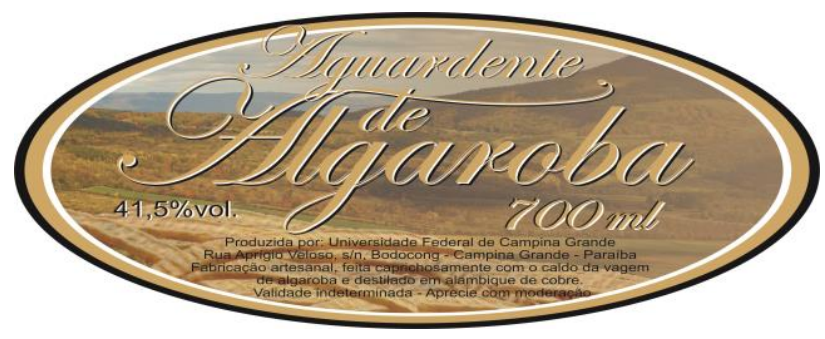

Apresenta-se, na Figura 5, a embalagem de aguardente de algaroba, com o rótulo projetado para este conceito e suas dimensões.

Figura 5. Imagens ilustrativas da criação da embalagem de vidro (Conceito 1) de aguardente com rótulo. a. vista frontal da embalagem e suas dimensões; b. vista lateral da embalagem e suas dimensões.
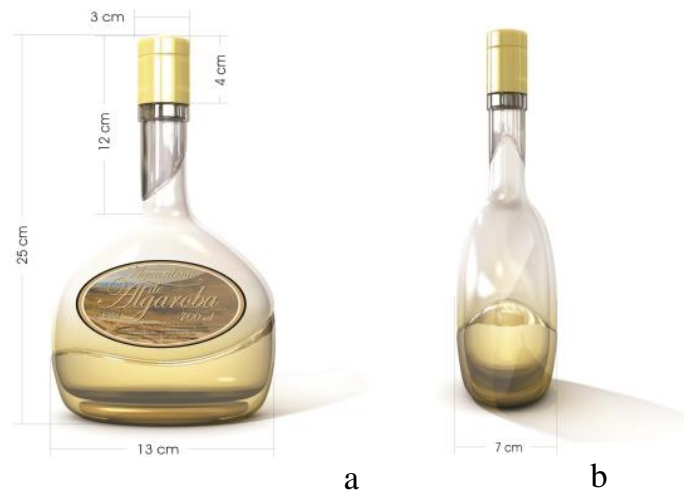


\section{CONCLUSÕES}

Através da análise sensorial detectou-se que quanto ao sabor não houve diferença para os avaliadores, sendo que a embalagem de vidro teve uma maior aceitação quanto à preferência em razão de conservar melhor as qualidades organolépticas da bebida que a embalagem PET e que este é o melhor material para o acondicionamento da aguardente; o conceito escolhido para a embalagem da aguardente de algaroba foi o conceito 1 , a embalagem que confere maior requinte com formas arredondadas que remetem à vagem da algaroba, apresentou uma diferença de apenas 3,1\% de preferência.

\section{REFERÊNCIAS BIBLIOGRÁFICAS}

ABREU, E. S.; SPINELLI, M. G. N.; A unidade de alimentação e nutrição. In.__. (Org.). Gestão de Unidade de Alimentação e Nutrição: um modo de fazer. São Paulo: Metha, 2011. p. 35-42.

BRASIL, Ministério da Agricultura, Pecuária e Abastecimento (MAPA). Instrução Normativa $n^{\circ} 15$, de 31 de março de 2011.

CÂMARA, M.; Cachaças: Bebendo e aprendendo: Guia prático de degustação. Rio de Janeiro: Mauadx, 2006. $192 \mathrm{p}$.

CARDELlO, H. M. A. B.; NASCIMENTO, R. F.; FRANCO, D. W.; FARIA, J. B. Changes in the volatile composition of sugar cane spirit during ageing in oak (Quercus sp) casks. In: Symposium on handling of environmental and biological samples in chromatography, 8.; Scientific Meeting Of The Group Of Chromatography And Related Techniques Of The Spanish Royal Society Of Chemistry, 26., 1997. p. 160

CARNEIRO, J. D. S; Opiniões e atitudes dos consumidores em relação a embalagens e rótulos de aguardente. Ciência e tecnologia de alimentos. v. 30, n. 3, p. 669673. 2010

DIAS, L. Cultura Engarrafada: rastros de Brasilidade nas Embalagens de Cachaça. http://reuni.univas.edu.br/Edicoes/201024/PDF/ArtigoLu cia.pdf

DORNELLES, A S.; RODRIGUES, S.; GARRUTI, D.S Aceitação e perfil ensorial das cachaças produzidas com Kefir e Saccharomyces cerevisae. Ciência Tecnologia de Alimentos, Campinas, 29(3): 518-522, jul.-set. 2009.

HOLANDA, V. B., FEITOSA, R. M., LINS, A. D. F., CAVALCANTE \& MATA, M. E. R. M. (2015). Avaliação da influência das embalagens de vidro e PET na qualidade da aguardente de algaroba (Prosopis juliflora (Sw.) DC.). Agropecuária Técnica, 36 (1), 156-160.

IBRAC (Instituto Brasileiro de Cachaça). O IBRAC. Site institucional. Brasília, 2008.
KUCHLER, Ivo L.; SILVA, Fernando Antônio M. Método potenciométrico para determinação de cobre em cachaça. Química Nova, v.22, n.3, p.339-341, May/Jun., 1999. ISSN 0100-4042

MINIM, Valéria Paula Rodrigues. Análise Sensorial: estudos com consumidores. Viçosa: Editora UFV, 2013.

MIRANDA, M. B. Avaliação físico-química de cachaças comerciais e estudo da influencia da irradiação sobre a qualidade da bebida em tonéis de carvalho. 2005, Dissertação (Mestrado em Ciências e Tecnologia de Alimentos)- Escola Superior de Agricultura "Luiz de Queiroz”. Universidade de São Paulo, Piracicaba.

SILVA, C. G.; Otimização do Processo de Produção da Aguardente de Algaroba e Aproveitamento dos Resíduos Sólidos em Produtos Alimentares. [Tese]. Campina Grande: Universidade Federal de Campina Grande; 2009.

SILVA, D. P. D.; SOUSA, J. P.; CAVALCANTI, R. M. F.; CLEMENTINO, L. da C.; SOUSA, B. R. S.; BRITO, A. F. de S.; QUEIROZ, J. C. F.; Produção artesanal de aguardente a partir de algaroba (Prosopis juliflora) e sua aceitação por consumidores. Revista Saúde e Ciência On Line, 2014; 3(3): 230-239, set-dez, 2014.

SOUZA, D.R.G.; A influência que as cores dos rótulos podem oferecer no ato da compra. Brasília: UniCeub; 2008. 